\section{OPEN ACCESS}

Edited by:

Daniel O'Connor,

University of Oxford, United Kingdom

Reviewed by:

Mildred Iro,

University of Southampton,

United Kingdom

Arvind Bagga,

All India Institute of Medical

Sciences, India

James McCaffrey,

Cambridge University Hospitals,

United Kingdom

*Correspondence:

Manuela Colucci

manuela.colucci@opbg.net

Specialty section

This article was submitted to

Vaccines and Molecular Therapeutics,

a section of the journal

Frontiers in Immunology

Received: 04 September 2020

Accepted: 16 February 2021

Published: 12 March 2021

Citation:

Colucci M, Piano Mortari E, Zotta F,

Corrente F, Concato C, Carsetti R,

Emma F and Vivarelli M (2021)

Evaluation of Immune and Vaccine

Competence in Steroid-Sensitive

Nephrotic Syndrome Pediatric

Patients. Front. Immunol. 12:602826.

doi: 10.3389/fimmu.2021.602826

\title{
Evaluation of Immune and Vaccine Competence in Steroid-Sensitive Nephrotic Syndrome Pediatric Patients
}

\begin{abstract}
Manuela Colucci ${ }^{*}$, Eva Piano Mortari ${ }^{2}$, Federica Zotta ${ }^{3}$, Francesco Corrente ${ }^{4}$, Carlo Concato ${ }^{5}$, Rita Carsetti $i^{2,4}$, Francesco Emma ${ }^{1,3}$ and Marina Vivarelli ${ }^{1,3}$
\end{abstract}

${ }^{1}$ Renal Diseases Research Unit, Genetics and Rare Diseases Research Area, Bambino Gesù Children's Hospital, IRCCS, Rome, Italy, ${ }^{2}$ Diagnostic Immunology Research Unit, Multimodal Medicine Research Area, Bambino Gesù Children's Hospital, IRCCS, Rome, Italy, ${ }^{3}$ Division of Nephrology, Department of Pediatric Subspecialties, Bambino Gesù Children's Hospital, IRCCS, Rome, Italy, ${ }^{4}$ Diagnostic Immunology Unit, Department of Laboratories, Bambino Gesù Children's Hospital, IRCCS, Rome, Italy, ${ }^{5}$ Division of Virology, Department of Laboratories, Bambino Gesù Children's Hospital, IRCCS, Rome, Italy

Idiopathic nephrotic syndrome is a childhood renal disease characterized by a damage of the glomerular filtration barrier leading to an intense leakage of proteins into the urine. This severe proteinuria causes a transient but strong reduction of serum IgG. Therefore, evaluation of vaccine competence by measuring serum levels of protective antibodies can be misleading in nephrotic syndrome, especially during the active phase of disease. To overcome this issue, in parallel to measuring serum antigen-specific lgG, we quantified by ELISPOT the number of antigen-specific memory B cells induced by previous immunization with tetanus and hepatitis B virus (HBV) in 11 steroid-sensitive nephrotic syndrome (SSNS) pediatric patients at onset before any immunosuppressive treatment (mean age $5.1 \pm 0.9$ years). Five age-matched children with non-immunomediated nephro-urologic disorders were also enrolled as controls (mean age 6.9 \pm 2.3 years). Low total serum lgG levels ( $<520 \mathrm{mg} / \mathrm{dl}$ ) were found in all the analyzed SSNS patients. In parallel, median levels of anti-tetanus and anti-HBV IgG were significantly reduced compared to controls [0.05 (0.03-0.16) vs. $0.45(0.29-3.10) \mathrm{IU} / \mathrm{ml}$ and $0.0(0.0-0.5)$ vs. $30.3(5.5-400.8) \mathrm{mlU} / \mathrm{ml}$, respectively; $p=0.02$ for both], with serum lgG titers below protective threshold in $7 / 11$ SSNS patients for tetanus and in 9/11 SSNS patients for HBV. In contrast, all SSNS patients had a competent B-cell response, showing an amount of total lgG-secreting B cells $>1,000$ counts $/ 10^{6}$ stimulated cells. The amount of anti-tetanus and anti-HBV lgG-secreting B cells was also comparable to that of controls ( $p=0.24, p=0.32$, respectively), with a frequency of memory anti-tetanus and anti-HBV IgG secreting B cells $>0.1 \%$ of total $\lg$ G secreting B cells. In conclusion, SSNS children at disease onset pre-immunosuppressive therapy showed a competent immune and vaccine response against tetanus and HBV, which can be 
correctly evaluated by quantification of antigen-specific memory B cells rather than by measuring serum lgG levels. This approach allows early identification of the impairment of immune and vaccine competence, which may derive from protracted use of different immunosuppressive drugs during disease course.

Keywords: vaccine competence, IgG, pediatric nephrology, steroid-sensitive nephrotic syndrome, immune competence, ELISPOT

\section{INTRODUCTION}

Idiopathic nephrotic syndrome (INS) is the most frequent glomerular disease in childhood. However, it has a rare incidence (1-17 cases per 100.000 children per year) (1). INS is characterized by a damage of the glomerular permeability barrier, which causes a severe leakage of proteins into the urine, associated with hypoalbuminemia and edema (1). A strong reduction of serum $\operatorname{IgG}$ associated with increased serum $\operatorname{IgM}$ levels is also frequent during the active phase of disease and sometimes persists also during remission $(2,3)$. Whether it depends on an impairment of the immune homeostasis or just on the intense proteinuria is debated (2-6). Several Tcell dysregulations have indeed been described both in relapse and in remission $(7,8)$ and altered levels of memory $B$ cells have been observed already at disease onset, before any immunosuppressive therapy (9). The reduction of protective antibodies observed in INS patients can also be dependent on the prolonged and intense immunosuppression administered in severe forms of the disease, increasing the risk for these patients to develop severe infections $(10,11)$. At disease onset, patients are treated with a standardized protocol of oral prednisone therapy, to which most patients respond within 4-6 weeks (defined as "steroid-sensitive nephrotic syndrome" patients, SSNS). Within the majority of pediatric patients affected by SSNS, clinical evolution can be extremely heterogeneous, ranging from non-relapsing to severely steroid-dependent forms, which require repeated cycles of steroid therapy and further immunosuppression with one or more steroid-sparing drugs, including anti-proliferative agents, calcineurin inhibitors and B-cell depleting drugs (1). This intense and prolonged immunosuppression can strongly impact immune and vaccine competence in severe forms of SSNS $(10,11)$. Whether this competence of SSNS pediatric patients is impaired only by the intense and prolonged immunosuppression required to maintain the disease remission or whether the intrinsic immune dysregulation can contribute to this impairment is not clear. Whatever the mechanism behind the lowering of serum IgG titers, this reduction hampers the correct evaluation of the immune and vaccine competence which is usually based on the dosage of total and antigen-specific serum IgG titers.

The aim of this pilot observational study is to evaluate the immune and vaccine competence of SSNS pediatric patients at disease onset, prior to any immunosuppressive treatment. To this purpose, we quantified antigen-specific memory B cells in parallel to the dosage of serum protective IgG.

\section{MATERIALS AND METHODS}

\section{Study Patients}

This monocentric observational study was conducted among INS pediatric patients followed from July 2018 to June 2020 at the Bambino Gesù Children's Hospital, IRCCS in Rome, Italy. The study was approved by our Ethics Committee and was conducted in compliance with the declaration of Helsinki. Written informed consent on behalf of the minors/children enrolled was obtained from parents. All patients at disease onset accessing our clinic in the study period and consenting to participate in the study were enrolled before starting oral prednisone therapy at a standard protocol of $60 \mathrm{mg} / \mathrm{m}^{2} /$ daily for 6 weeks followed by $40 \mathrm{mg} / \mathrm{m}^{2} /$ every other day for 6 weeks. Patients were then monitored for the response to prednisone therapy and defined "steroid-sensitive" (SSNS) if they responded within 4 weeks by showing negative proteinuria on urine dipstick for $\geq 3$ days (12). Patients who did not respond to the standardized prednisone therapy within 4 weeks [defined as "steroid-resistant" (12)] were subsequently excluded. Excluding criteria were also chronic infections, previous treatment with immunosuppressive drugs (excluding low dose steroids for periods $<3$ months), age $>18$ years. Renal biopsy was considered only for patients $\leq 1$ or $\geq 12$ years old, sustained elevation of serum creatinine or findings indicative of another immune-mediated disorder (1). Agematched non immune-mediated nephro-urologic disorders were also evaluated as controls (CTRL). Clinical and demographical characteristics were registered.

\section{Cell Collection}

An additional blood sample to perform the evaluation of immune and vaccine competence was obtained at the first hospital admission for SSNS patients and during routine visits for CTRL. Peripheral blood mononuclear cells (PBMCs) were isolated by Ficoll-Paque Plus (Amersham Biosciences) densitygradient centrifugation and cryopreserved in liquid nitrogen up to analysis.

\section{CpG Stimulation and ELISPOT}

This assay was performed on previously anonymized samples in a blinded fashion in order to minimize a potential bias of data analysis. Immune and vaccine competence were determined by evaluating the ability of stimulated B cells to produce total and antigen-specific immunoglobulins, respectively.

PBMCs were cultured in complete medium at a concentration of $1 \times 10^{6}$ cells $/ \mathrm{ml}$. Complete medium was prepared as follows: RPMI-1640 (Euroclone), 10\% heat inactivated fetal bovine 
serum (FBS, Hyclone Laboratories), 1\% L-Glutammine (GIBCO BRL); $1 \%$ Penicillin/Streptomicin $100 \times$ (Euroclone), $1 \%$ sodium pyruvate (GIBCO BRL).

Cells were stimulated for 5 days with $0.35 \mu \mathrm{M}$ TLR9 agonist CpG-B ODN2006 (Hycult Biotech) plus $20 \mathrm{ng} / \mathrm{ml}$ rhIL-21 (Milteny) and $20 \mathrm{ng} / \mathrm{ml}$ rhIL-4 (Milteny).

For the simultaneous detection of $\operatorname{IgM}$ and $\operatorname{IgG}$ we used the Human IgG/IgM Dual-Color B Cell ELISpot Kit (R\&D System). This kit is designed for the simultaneous detection of total and antigen specific IgM and IgG.

For the detection of total IgG and IgM polyclonal antibodies specific for human IgG and IgM, respectively, were coated onto a polyvinylidene difluoride (PVDF)-backed microplate following manufacturer's instructions. For the detection of antigen specific memory B cells microplate were coated overnight with recombinant hepatitis B surface Ag (HbsAg adw), (Prospec) and with synthetic tetanus toxin peptide (C-term), (OriGene).

PBMCs stimulated for 5 days, as described before, were collected, counted and seeded in the coated plates. Plates were left at $37^{\circ} \mathrm{C}, 2 \% \mathrm{CO}_{2}$ for overnight to allow antibody secretion. A total of three 1:2 serial dilutions were done starting in the first well with $2 \times 10^{4}$ cells for detection of total IgG and IgM. A total of $2 \times 10^{5}$ cells were seeded in the first dilution well (three 1:2 serial dilutions) for the detection of $\mathrm{B}$ cells secreting specific antibodies.

After washing, a horseradish peroxidase-conjugated polyclonal antibody specific for $\operatorname{IgG}$ and a biotinylated polyclonal antibody specific for human IgM were added to the wells. Following a wash, alkaline-phosphatase conjugated to streptavidin was added and a substrate solution (BCIP/NBT) was added. After washing the BCIP/NBT from the wells with deionized water, an AEC chromogen solution was added to the wells. A red precipitate and a blue-black colored precipitate formed and appeared as spots, with each red spot representing an individual IgG secreting cell and each blue spot representing an individual IgM secreting cell. Plates were left to dry before counting with an ELISCAN (A-EL-VIS).

\section{Laboratory Analytes}

Hematology (serum protein, serum albumin, serum creatinine, $\mathrm{C}$ reactive protein) and urinary (protein-to-creatinine ratio) parameters and serum IgG, IgA, IgM, anti-tetanus IgG and anti- hepatitis B virus (HBV) IgG were measured as routine analysis. Normal ranges for serum IgG (520-1,500 $\mathrm{mg} / \mathrm{dl})$, $\operatorname{IgA}(36-320 \mathrm{mg} / \mathrm{dl})$ and $\operatorname{IgM}(35-155 \mathrm{mg} / \mathrm{dl})$ as well as antibody titers determining sufficient (protective) immunization against $\mathrm{HBV}(>10 \mathrm{mIU} / \mathrm{ml})$ and tetanus $(>0.6 \mathrm{IU} / \mathrm{ml})$ were indicated in the diagnostic laboratory of Bambino Gesù Children's Hospital - IRCCS. Range for antibody titers representing an existing (but not sufficient) immunization against tetanus $(0.1-0.6 \mathrm{IU} / \mathrm{ml})$ was also reported (13).

\section{Statistical Analyses}

This is a single center, pilot study. As there is no null hypothesis to test, no formal sample size calculation was performed. Continuous data were expressed as mean \pm standard error of the mean (SEM) if they passed normality test (Shapiro-Wilk test), or medians and interquartile range otherwise; categorical data were represented as numbers and percentages. Differences between groups were compared by unpaired $t$-test for normally distributed data or by Mann-Whitney $U$ test for non-parametric data; Fisher exact test was used to compare proportions of patients in different categorical variables. $P$-values $<0.05$ were considered significant. Analyses were performed through the software GraphPad Prism 6.

\section{RESULTS}

\section{Patient Characteristics}

Twelve INS patients (five males and seven females) at disease onset were enrolled for the current study. One patient who did not respond to steroid treatment within 4 weeks was subsequently excluded from the analysis, which was performed on the remaining 11 SSNS patients. Five age-matched controls (three males and two females) with non-immune-mediated nephro-urologic disorders (one chronic kidney disease, one kidney stone, one kidney hypodysplasia, two nephrocalcinosis with hypercalcemia) were also enrolled. Mean time to remission of SSNS patients was $8.0 \pm 0.6$ days from starting prednisone treatment. Table 1 summarizes demographical and clinical characteristics. Mean age was $5.1 \pm 0.9$ years for SSNS patients and 6.9 \pm 2.3 years for CTRL. Only one SSNS patient underwent renal biopsy since he was $\geq 12$ years old at onset and presented a histological pattern suggestive of minimal change disease. As expected, serum protein and serum albumin were significantly lower and proteinuria was significantly higher in SSNS patients compared to CTRL (Table 1). Serum

TABLE 1 | Characteristics of study patients.

\begin{tabular}{|c|c|c|c|c|}
\hline Parameter & Unit & $\begin{array}{c}\text { SSNS at } \\
\text { onset } \\
(n=11)\end{array}$ & CTRL $(n=5)$ & $P$-value \\
\hline \multicolumn{5}{|l|}{ Demographics } \\
\hline Age & Years & $5.1 \pm 0.9$ & $6.9 \pm 2.3$ & 0.38 \\
\hline Male sex & $N(\%)$ & $5(45)$ & $3(60)$ & 1.0 \\
\hline \multicolumn{5}{|l|}{ Clinical characteristics } \\
\hline Serum Protein & $g / d l$ & $4.1 \pm 0.1^{\star}$ & $6.9 \pm 0.2$ & $<0.001$ \\
\hline Serum albumin & $g / d l$ & $2.2 \pm 0.1^{\star}$ & $4.7 \pm 0.1$ & $<0.001$ \\
\hline Serum Creatinine & mg/dl & $0.3[0.2-0-4]$ & $0.4[0.3-1.8]$ & 0.11 \\
\hline $\begin{array}{l}\text { C reactive protein }>0.5 \\
\mathrm{mg} / \mathrm{dl}\end{array}$ & $N(\%)$ & $0(0)$ & $0(0)$ & - \\
\hline $\begin{array}{l}\text { Urinary } \\
\text { protein-to-creatinine } \\
\text { ratio }\end{array}$ & $\mathrm{mg} / \mathrm{mg}$ & $18.3 \pm 4.1$ & $0.2 \pm 0.1$ & 0.01 \\
\hline Time to remission & Days & $8.0 \pm 0.6$ & - & - \\
\hline
\end{tabular}

Continuous data are expressed as mean \pm standard error of the mean or median [interquartile range] and compared by unpaired t test or Mann-Whitney U test, respectively. Categorical values are indicated as absolute count and percentage, compared by a Fisher's exact test. SSNS, steroid-sensitive nephrotic syndrome; CTRL, control group. *All SSNS patients had already received albumin infusions at time of sampling. The bold numbers highlight the significant differences. 


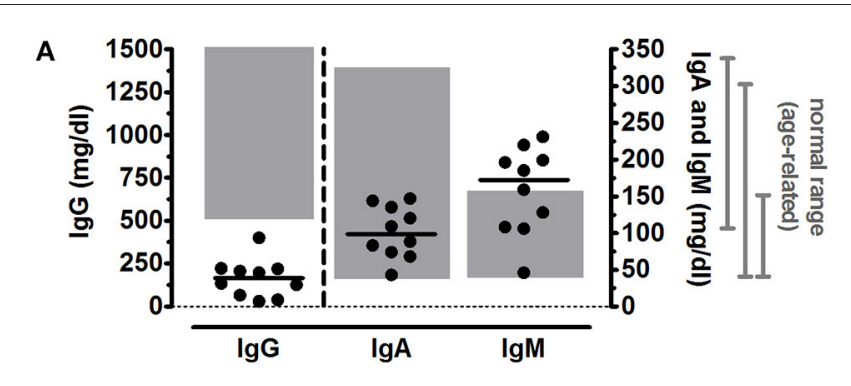

B

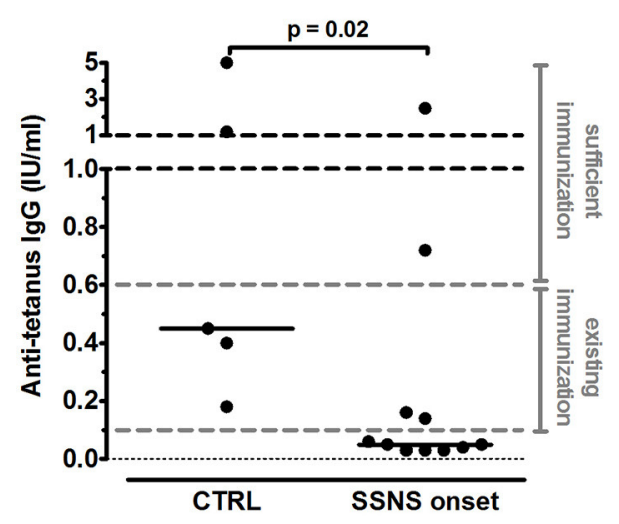

C

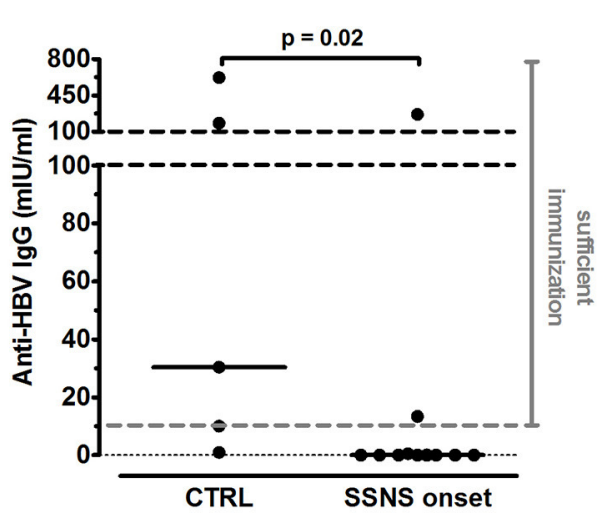

FIGURE 1 | Serum immunoglobulin levels in steroid-sensitive nephrotic syndrome pediatric patients at onset. (A) Levels of total serum IgG, IgA and IgM were measured in steroid-sensitive nephrotic syndrome pediatric patients at disease onset (SSNS, $n=10 / 11$ ) and expressed as mg/dl. In one patient serum immunoglobulin levels were not determined. Each plot represents a different patient. Gray areas represent the age-related normal range as indicated by the diagnostic laboratory of Bambino Gesù Children's Hospital, IRCCS. (B,C) Antigen-specific IgG titers against (B) tetanus and (C) hepatitis B virus (HBV) were measured in SSNS pediatric patients at onset $(n=11)$ and in age-matched controls (CTRL, $n=5)$ and expressed as IU/ml and mlU/ml, respectively. Protective levels identified by dashed gray lines were indicated in the diagnostic laboratory of Bambino Gesù Children's Hospital, IRCCS. Horizontal lines indicate the medians and differences between groups were compared using the Mann-Whitney $U$ test.

levels of C-reactive protein were normal $(<0.5 \mathrm{mg} / \mathrm{dl})$ in all patients.

\section{Serum Immunoglobulin Levels and Immune and Vaccine Competence}

All patients were previously vaccinated against tetanus and HBV as per national requirements (14): in the first year of age, all children received three doses of both tetanus and HBV vaccines; a fourth booster dose of tetanus vaccine was administered in 4 SSNS patients and in 2 CTRL who were older than 6 years. Mean time elapsed since last immunization was not significantly different between the two groups both for tetanus $(2.5 \pm 0.5$ years for SSNS patients vs. $4.2 \pm 1.2$ years for CTRL, $p=0.13)$ and HBV $(4.1 \pm 0.9$ years for SSNS patients vs. $6.0 \pm 2.3$ for CTRL, $p=0.38)$. Serum IgG were below the age-related normal range (520-1,500 mg/dl) in 10/10 analyzed SSNS patients (mean levels $=164.3 \pm 35.0 \mathrm{mg} / \mathrm{dl}$ ) and serum IgM were higher than age-related normal range (35$155 \mathrm{mg} / \mathrm{dl}$ ) in 6/10 SSNS patients (mean levels $=157.8 \pm 18.8$ $\mathrm{mg} / \mathrm{dl}$ ) (Figure 1A). In contrast, no alteration was observed in serum IgA levels (mean levels $=101.1 \pm 11.2 \mathrm{mg} / \mathrm{dl}$ ) (Figure 1A).

Serum anti-tetanus IgG titers were below the level of sufficient protection $(0.6 \mathrm{IU} / \mathrm{ml})$ in $9 / 11$ SSNS patients and below the existing protection $(0.1 \mathrm{IU} / \mathrm{ml})$ in $7 / 11$ SSNS patients, respectively (Figure 1B) and median levels were significantly reduced in SSNS patients compared to CTRL (0.05 [0.03-0.16] vs. 0.45 [0.29-3.10] IU/ml, $p=0.02$; Figure 1B). In parallel, serum anti-HBV IgG titers were undetectable in $9 / 11$ SSNS patients (Figure 1C) and were significantly lower in SSNS patients compared to CTRL $[0.0(0.0-0.5)$ vs. $30.3(5.5-400.8) \mathrm{mIU} / \mathrm{ml}$, $p=0.02$, Figure $1 \mathrm{C}]$.

In contrast to the reduced levels of serum IgG, SSNS patients showed an intact B-cell memory pool as demonstrated by the competent immune response to polyclonal stimulation (Figure 2A). The amount of total IgG-secreting B cells was $>1,000$ counts $/ 10^{6}$ stimulated cells in all SSNS patients and, despite interpersonal variability, no significant difference was observed as compared to CTRL ( $p=0.78$, Figure 2A). In parallel, also a competent memory B-cell response against tetanus and HBV was observed in SSNS patients compared to CTRL $(p=0.24$, Figure $2 \mathrm{~B}$ and $p=0.32$, Figure $2 \mathrm{D}$, respectively), with a frequency of memory anti-tetanus and anti-HBV IgG secreting B cells $>0.1 \%$ of total IgG secreting $\mathrm{B}$ cells $(p=0.14$ and $\mathrm{p}=0.17$, respectively, compared to CTRL, Figures 2C,E). A competent response was observed also for IgM-secreting B cells (> 10,000 counts $/ 10^{6}$ stimulated cells of total IgM-secreting B cells in both groups; $p=0.99$, 


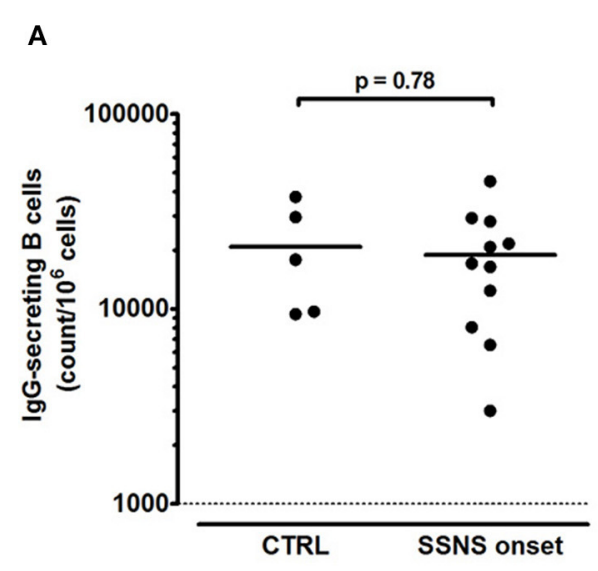

B

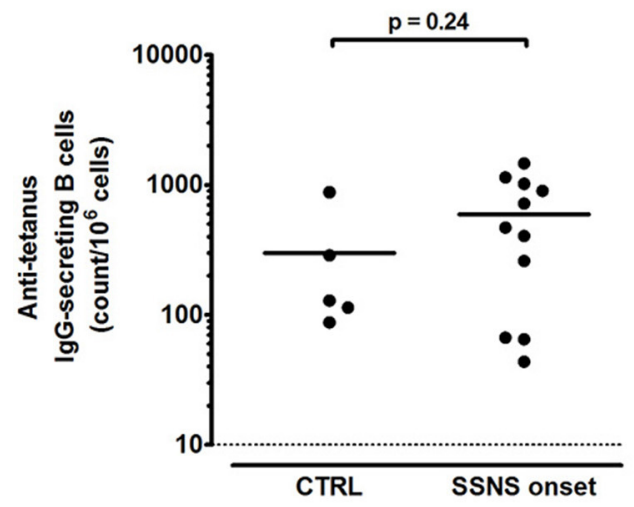

D

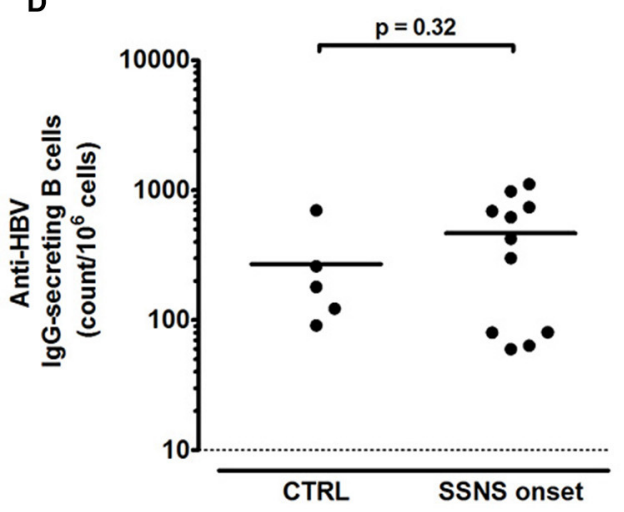

C

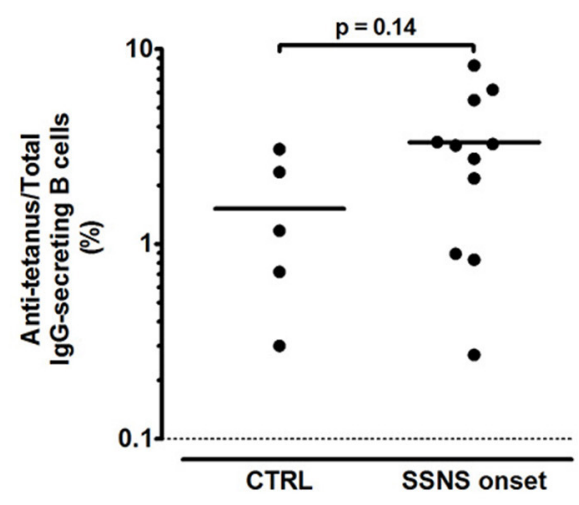

E

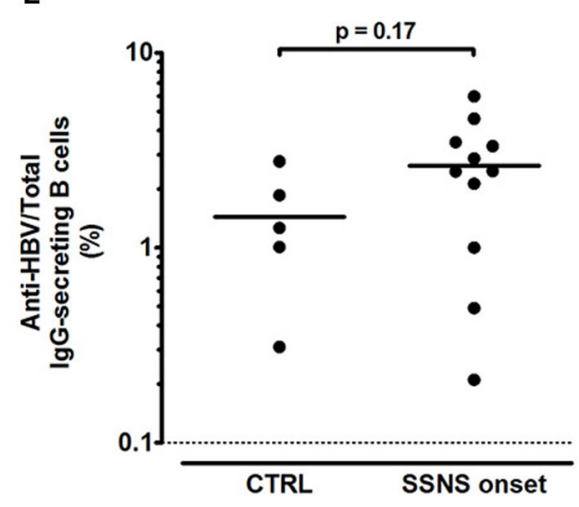

FIGURE 2 | Total and antigen-specific IgG-secreting B cells in steroid-sensitive nephrotic syndrome pediatric patients at onset. (A-E) Isolated PBMCs were stimulated for 5 days with CpG plus rhlL-21 and rhlL-4. Following stimulation, $(\mathbf{A})$ total, $(\mathbf{B}, \mathbf{C})$ anti-tetanus and $(\mathbf{D}, \mathbf{E})$ anti-HBV IgG-secreting B cells were enumerated by ELISPOT in steroid-sensitive nephrotic syndrome pediatric patients at disease onset (SSNS, $n=11$ ) and in age-matched controls (CTRL, $n=5$ ). Antigen-specific memory B cells were represented as (B,D) absolute count $/ 10^{6}$ cells and as $\mathbf{( C , E ) ~ p e r c e n t a g e ~ o f ~ t o t a l ~ l g G - s e c r e t i n g ~ B ~ c e l l s . ~ E a c h ~ p l o t ~ r e p r e s e n t s ~ a ~ d i f f e r e n t ~ p a t i e n t . ~}$ Horizontal lines indicate the means and differences between groups were compared using the unpaired $t$ test. 
SSNS vs. CTRL), with a frequency of memory anti-tetanus and anti-HBV IgM secreting $B$ cells $>4 \%$ of total IgM secreting B cells ( $p=0.83$, SSNS vs. CTRL for both vaccinespecific responses).

\section{DISCUSSION}

The current study focuses on SSNS pediatric patients at disease onset, prior to any immunosuppressive treatment, in order to investigate the immune and vaccine competence of SSNS patients without confounding effects exerted by an intense immunosuppression steroids, anti-proliferative agents, calcineurin inhibitors and/or B-cell depleting drugs, usually administered in severe forms of SSNS to avoid recurrence of the disease (1). Many reports already investigated the response to previous and subsequent vaccination in INS children and found a reduction of seroprotection induced by previous immunization and an impaired immunogenicity of vaccines administered following the onset of the disease (15-19). However, most of these studies evaluated the levels of vaccine-specific antibodies of INS patients who were under an intense immunosuppression, which can strongly impact the immune response (10). As reported, high-dose prednisone or steroid-sparing agents administered at time of HBV vaccination impair the antibody response (16, 17). In contrast, patients who were vaccinated before starting immunosuppression partially preserve protective titers of antiHBV IgG (16). However, anti-HBV and anti-tetanus antibodies induced by previous immunization are strongly reduced by a prolonged and intense immunosuppression and by B-cell depletion in INS children $(11,20)$. B-cell depleting agents are indeed able to efficiently eliminate the circulating memory B-cell subsets, especially in INS patients who received this treatment at an early age (11). Of note, re-immunization following Bcell depletion (after B-cell reappearance) can be effective in restoring vaccine competence in treated patients (11). Another factor that confounds the evaluation of protective antibodies in INS is the reduction of serum IgG that can be dependent on the leakage of immunoglobulins into the urine during the active phase of disease or on an intrinsic immune dysregulation specific of INS patients $(2-7,9)$. Accordingly, we observed reduced total and anti-tetanus and anti-HBV IgG titers. To overcome this relevant bias, in parallel to the determination of serum vaccine-specific IgG titers, we quantified the number of vaccine-specific memory B cells by an ELISPOT assay. With this approach, we found that circulating $B$ cells in our cohort were highly effective in responding to polyclonal stimulation by producing a large amount of total IgG and IgM. We also observed a competent vaccine-specific memory Bcell response against previous tetanus and HBV immunization. Our study demonstrates that SSNS patients have a competent immune response and a preserved immune memory to previous vaccination against tetanus and $\mathrm{HBV}$ at disease onset, before any immunosuppressive therapy.

The main limitation of this study is the limited number of the enrolled patients at disease onset, due to the rarity of the disorder and to the monocentric nature of this pilot study. However, the selection of SSNS patients at onset, prior to any immunosuppression, was necessary to avoid confounding effects of immunosuppressive therapy. More importantly, the experimental approach to quantify the amount of IgG-secreting memory B-cells permitted to overcome the bias of leaked serum IgG into the urine and to correctly evaluate the immune and vaccine competence of the study cohort.

In conclusion, our study demonstrates that SSNS pediatric patients show a preserved immune and vaccine competence at disease onset, which can be efficiently evaluated by quantifying antigen-specific memory $\mathrm{B}$ cell response rather than by measuring serum IgG titers. This approach allows early identification of the impairment of the immune and vaccine competence that a protracted use of different immunosuppressive drugs may determine during disease course. Moreover, it overcomes the bias deriving from urinary leakage of serum protein, given that the amount of memory B cells is not affected by proteinuria. Further investigations are necessary to validate our results in a larger cohort of SSNS patients at disease onset and to identify which immunosuppressive drugs affect the vaccine-specific memory B-cell response.

\section{DATA AVAILABILITY STATEMENT}

The raw data supporting the conclusions of this article will be made available by the authors, without undue reservation.

\section{ETHICS STATEMENT}

The studies involving human participants were reviewed and approved by Bambino Gesù Children's Hospital, IRCCS, Ethics Committee. Written informed consent to participate in this study was provided by the participants' legal guardian/next of kin.

\section{AUTHOR CONTRIBUTIONS}

MC designed the study, performed data analysis, and manuscript preparation. EP performed data experiments, data analysis, and helped with manuscript preparation. FZ helped with collection of study samples, clinical information, and manuscript preparation. FC and CC helped with experiments and data interpretation. RC, $\mathrm{FE}$, and MV helped with study design, data interpretation, and manuscript preparation. All authors approved the final version of the manuscript.

\section{FUNDING}

This work was supported by the 2018 European Society of Pediatric Nephrology Research Grant Program (Grant number ESPN \#4.2018) and by the Ricerca Corrente of the Italian Ministry of Health. 


\section{REFERENCES}

1. Noone DG, Iijima K, Parekh R. Idiopathic nephrotic syndrome in children. Lancet. (2018) 392:61-74. doi: 10.1016/S0140-6736(18)30536-1

2. Giangiacomo J, Cleary TG, Cole BR, Hoffsten P, Robson AM. Serum immunoglobulins in the nephrotic syndrome. A possible cause of minimal-change nephrotic syndrome. N Engl J Med. (1975) 293:8-12. doi: 10.1056/NEJM197507032930103

3. Beale MG, Nash GS, Bertovich MJ, MacDermott RP. Immunoglobulin synthesis by peripheral blood mononuclear cells in minimal change nephrotic syndrome. Kidney Int. (1983) 23:380-6. doi: 10.1038/ki.1983.30

4. Heslan JM, Lautie JP, Intrator L, Blanc C, Lagrue G, Sobel AT. Impaired IgG synthesis in patients with the nephrotic syndrome. Clin Nephrol. (1982) 18:144-7.

5. Schnaper HW. The immune system in minimal change nephrotic syndrome. Pediatr Nephrol. (1989) 3:101-10. doi: 10.1007/BF00 859637

6. Kemper MJ, Altrogge H, Ganschow R, Müller-Wiefel DE. Serum levels of immunoglobulins and IgG subclasses in steroid sensitive nephrotic syndrome. Pediatr Nephrol. (2002) 17:413-7. doi: 10.1007/s00467-0010817-7

7. Lama G, Luongo I, Tirino G, Borriello A, Carangio C, Esposito Salsano M. T-lymphocyte populations and cytokines in childhood nephrotic syndrome. Am J Kidney Dis. (2002) 39:958-65. doi: 10.1053/ajkd.2002. 32769

8. Kemper MJ, Meyer-Jark T, Lilova M, Müller-Wiefel DE. Combined T- and B-cell activation in childhood steroid-sensitive nephrotic syndrome. Clin Nephrol. (2003) 60:242-7. doi: 10.5414/cnp60242

9. Colucci M, Carsetti R, Cascioli S, Serafinelli J, Emma F, Vivarelli M. B cell phenotype in pediatric idiopathic nephrotic syndrome. Pediatr Nephrol. (2019) 34:177-181. doi: 10.1007/s00467-018-4095-z

10. Banerjee S, Dissanayake PV, Abeyagunawardena AS. Vaccinations in children on immunosuppressive medications for renal disease. Pediatr Nephrol. (2016) 31:1437-48. doi: 10.1007/s00467-015-3219-y

11. Colucci M, Carsetti R, Serafinelli J, Rocca S, Massella L, Gargiulo A, et al. Prolonged impairment of immunological memory after anti-CD20 treatment in pediatric idiopathic nephrotic syndrome. Front Immunol. (2019) 10:1653. doi: 10.3389/fimmu.2019.01653

12. Vivarelli M, Massella L, Ruggiero B, Emma F. Minimal change disease. Clin J Am Soc Nephrol. (2017) 12:332-45. doi: 10.2215/CJN.05000516
13. Matousková I, Matlerová S, Janoutová G, Janout V. Persistence of antibodies against tetanus upon revaccination. Cent Eur J Public Health. (2005) 13:99102.

14. Giovanni Gabutti, Parvanè Kuhndari, Armando Stefanati. Italian immunization calendar: rationale and schedule. Ital J Pediatr. (2015) 41(Suppl 1):A12. doi: 10.1186/1824-7288-41-S1-A12

15. La Manna A, Polito C, Foglia AC, Di Toro A, Cafaro MR, Del Gado R. Reduced response to hepatitis B virus vaccination in boys with steroid-sensitive nephrotic syndrome. Pediatr Nephrol. (1992) 6:251-3. doi: 10.1007/BF00878360

16. Mantan M, Pandharikar N, Yadav S, Chakravarti A, Sethi RG. Seroprotection for hepatitis B in children with nephrotic syndrome. Pediatr Nephrol. (2013) 28:2125-30. doi: 10.1007/s00467-013-2538-0

17. Yildiz N, Sever L, Kasapçopur Ö, Çullu F, Arisoy N, Çalişkan S. Hepatitis B virus vaccination in children with steroid sensitive nephrotic syndrome: immunogenicity and safety? Vaccine. (2013) 31:3309-12. doi: 10.1016/j.vaccine.2013.05.004

18. Liakou CD, Askiti V, Mitsioni A, Stefanidis CJ, Theodoridou MC, Spoulou VI. Safety, immunogenicity and kinetics of immune response to 7 -valent pneumococcal conjugate vaccine in children with idiopathic nephrotic syndrome. Vaccine. (2011) 29:6834-7. doi: 10.1016/j.vaccine.2011.07.053

19. Goonewardene ST, Tang C, Tan LT, Chan KG, Lingham P, Lee L-H, et al. Safety and efficacy of pneumococcal vaccination in pediatric nephrotic syndrome. Front Pediatr. (2019) 7:339. doi: 10.3389/fped.2019.00339

20. Bonanni A, Calatroni M, D’Alessandro M, Signa S, Bertelli E, Cioni M, et al. Adverse events linked with the use of chimeric and humanized antiCD20 antibodies in children with idiopathic nephrotic syndrome. Br J Clin Pharmacol. (2018) 84:1238-49. doi: 10.1111/bcp.13548

Conflict of Interest: The authors declare that the research was conducted in the absence of any commercial or financial relationships that could be construed as a potential conflict of interest.

Copyright (c) 2021 Colucci, Piano Mortari, Zotta, Corrente, Concato, Carsetti, Emma and Vivarelli. This is an open-access article distributed under the terms of the Creative Commons Attribution License (CC BY). The use, distribution or reproduction in other forums is permitted, provided the original author(s) and the copyright owner(s) are credited and that the original publication in this journal is cited, in accordance with accepted academic practice. No use, distribution or reproduction is permitted which does not comply with these terms. 